\title{
Entrepreneurial motivation: the impact of cultural capital on the 'who' is motivated
}

\author{
Warren Lloyd \\ Department of Management, Science and Technology, \\ Open University Netherlands, \\ Valkenburgerweg 177, 6419 AT, \\ Heerlen, Netherlands \\ Email: warrenlloyd@ziggo.nl
}

\begin{abstract}
Almost all definitions propose entrepreneurs as especially motivated and talented individuals. Therefore, understanding and explaining the psychological forces within the individual that motivates them is highly desired. This paper is intended to investigate studies on entrepreneurial motivation to identify an effective theory that enables recognising 'who' could potentially become an entrepreneur, rather than 'how' and 'why' individuals choose to become entrepreneurs. Of the theories discussed, McClelland's achievement need (n-ach) is accepted as the most apt in this review. It is further noted in this paper that in defining and explaining this need, and its influence on entrepreneurship, an understanding of the impact of an individual's culture, beliefs and attitudes, encompassed in their cultural capital, is required. Primarily by evaluation of literature in this report, strong evidence indicates and supports the distinctive impact of culture on entrepreneurial motivation. In conclusion, a framework is proposed for further study investigating the impact of cultural capital on $\mathrm{n}$-ach in home and immigrant entrepreneur cultural groups.
\end{abstract}

Keywords: entrepreneurial motivation; McClelland achievement need theory; opportunity and necessity entrepreneurship; entrepreneurial intent; cultural capital; cultural groups; immigrant entrepreneurship.

Reference to this paper should be made as follows: Lloyd, W. (2019) 'Entrepreneurial motivation: the impact of cultural capital on the 'who' is motivated', Int. J. Business and Globalisation, Vol. 23, No. 1, pp.139-152.

Biographical notes: Warren Lloyd is a $\mathrm{PhD}$ candidate at the Open University Netherlands, he currently writing his thesis on the impact of cultural capital on achievement need motivation in home culture, and their descending immigrant groups, under differing macro-economic policy environments. He focuses on publishing primarily in International Journal of Business and Globalisation, and International Journal of Entrepreneurship and Small Business.

\section{Introduction}

The value of new business creation and growth through entrepreneurs is vital for economic development. Understanding not just what motivates individuals towards entrepreneurship, but who to target policies and incentives towards, is critical for institutions and policymakers. It had been suggested [Carsrud and Brannback, (2011), 
p.9] that often entrepreneurial motivation is a topic which seems to have been abandoned in numerous earlier studies, without being fully investigated. And further advocated is that the accumulated knowledge from social science disciplines being built on may have impeded research on entrepreneurial motivation.

In contrast to this thinking though, [Ucbasaran et al., (2010), p.541] it has been posed that recent day scholars may often draw upon cognitive psychology in understanding the psychological foundations of entrepreneurial behaviour, and that research into the field of entrepreneurship using these principles of cognitive psychology has, in fact become a significant sub-field of study. Further emphasised [Dimitratos et al., (2015), p.1] is the cognitive perspective of entrepreneurs, in that motivation could very well be the distinction between those individuals who evaluate and act on opportunities from those individuals who do not. And although certain universal principles cut across cultural borders [Urban, (2007), p.82] it had been stated that there too exists a significant difference of entrepreneurial rates amongst different groups. As too suggested [Dana, (1996), p.65], cultural perception of opportunity affects the individual's response to the opportunity, and therefore is a highly relevant causal variable.

In this paper it is intended to investigate studies on entrepreneurial motivation to identify an effective theory that enables recognising 'who' could potentially become an entrepreneur, rather than 'how' and 'why' individuals choose to become entrepreneurs. Along with this, defining and attempting to measure the motivation of individuals could not be considered complete without investigating and understanding the behaviours and attitudes, commonly known as the culture, of the groups within same and different countries and regions. Understanding the impact of different group's cultural capital on the behaviour and relative motivation levels in their individuals, could be as important as any theory on the motivation itself.

\section{Defining the modern day entrepreneur}

The concept 'entrepreneurship' is highly complex, with no one concise definition. At its core is the entrepreneur, the individual described for the modern day [Zimmerer and Scarborough, (2008), p.5] as an individual who creates a new business for the purpose of achieving growth and profit, despite risk and uncertainty, by identifying and assembling the resources to capitalise on an opportunity. Similarly, a simplified definition of entrepreneurship was identified through a study on 308 business founders [Kirkwood, (2001), p.22] to be; "anyone who has founded his or her own business". Since the early 1900 's, definitions of an entrepreneur have evolved naturally, extended to include terms such as 'economic agents', 'manager of resources' and 'innovator' to name but a few. Fundamental though to almost all the definitions since, is that entrepreneurs are especially motivated and talented individuals [Alam and Hossan, (2003), p.1].

\section{Entrepreneurial motivation studies}

In investigating entrepreneurial behaviour [Hessels et al., (2008), p.323], four types of study categories were identified from research, broadly covered as: 
1 studies of reasons to start a business, classified as either opportunity or necessity

2 cost-benefit types, explaining the intent to start a business

3 multinomial-type investigations, explaining the odds of being in a certain stage of the entrepreneurial process versus not considering entrepreneurship at all (this includes and aligns with entrepreneurial intent)

4 in-depth psychological motives, such as studies on the need for achievement.

These categories are outlined in Figure 1, with the construct providing an illustrative roadmap through the relevant literature and theories that are discussed in this paper, proposing the most apt theory to identify the 'who' is motivated to become an entrepreneur.

Figure 1 Identification of the 'who' through motivational studies

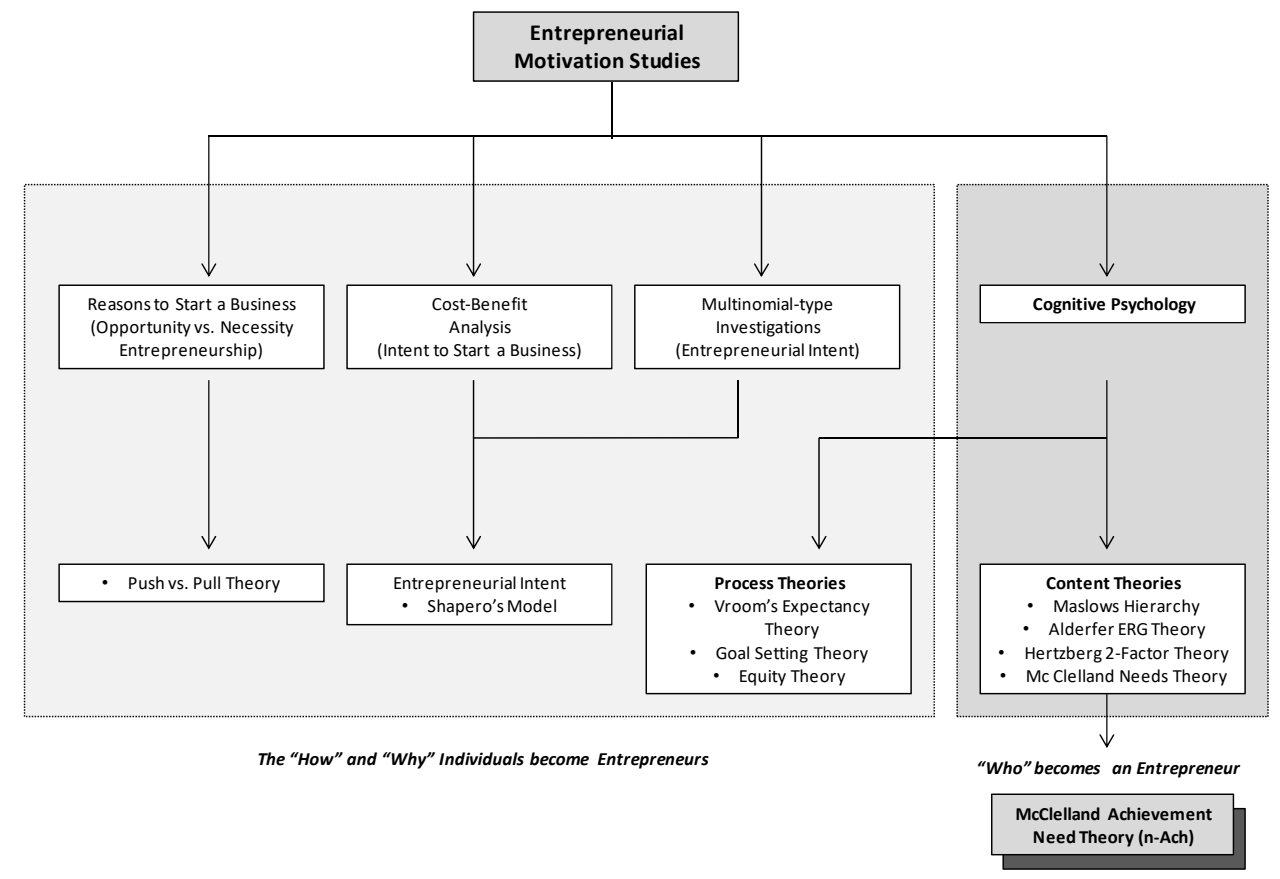

Under the first category, and understanding the reasons to start a business, [Dana, (1997), p.52] the forces influencing self-employment can be proposed under three variables, namely: the self, reflecting personality determined behaviour; the ethno-cultural milieu, focused on culturally influenced behaviour; and the host society, discussed as marginality-compensatory response behaviour. An addition fourth school of thought noted is the interaction between ethno-cultural milieu and the host society, termed ethnicity-enhanced adaptive behaviour. Dana's study suggests that the 'entrepreneurial spirit' may be either orthodox (cultural) or reactionary (circumstantial), concluding that attempting to explain ethnic enterprise as a function of just one causal variable may be insufficient. Understanding these forces then, aligns with the over-arching conceptualisation of entrepreneurial motivation, discussed as differentiated into necessity 
(push) and opportunity (pull) entrepreneurship [Stephan et al., (2015), p.1]. The 'necessity' refers to the belief that an individual's own business effort or opportunity offers the highest likely utility versus employment opportunities, or lack thereof, and the term 'opportunity' arises from an innovative idea or opportunity presented [Valdez et al., (2011), p.145]. The significant distinction as this relates to entrepreneurship is that whether initiated by either 'push' or 'pull' factors, an opportunity is nevertheless required to be identified, and acted on, by the entrepreneur in order to start a new business or venture [Solymossy, (2005), p.501].

In a paper explaining engagement levels of opportunity and necessity entrepreneurs [Bhola et al., (2006), p.1] a distinction was made between the two in their effort to measure the rate of entrepreneurial activity across countries. And although these theories support explaining where and why entrepreneurship occurs, they are somewhat unclear in approach to actually measuring the motivation of respective entrepreneurs, with it being stated [Kreuger et al., (2000), p.411] that the prediction of entrepreneurial activity by modelling extrinsic factors more often results in inadequate explanatory power. Along with this, [Stephan et al., (2015), p.1] it has been acknowledged of these theories that; "approach and avoidance motivation are at work simultaneously as no goal has only positive aspects". This then explains why combinations of both opportunity and necessity entrepreneurship are seen in practice, and the indicators of both can be identified in a number of the literature reviewed through this paper. An example of this illustrated [Dana and Riseth, (2011), p.108] in a paper on Reindeer herders in Finland. In the paper, it was emphasised that although non-Sami entrepreneurs raised reindeer for economic motives, Sami herders were both pulled to community based and culturally valuable reindeer herding, but were too pushed towards individualistic firms out of necessity.

In the second category titled cost-benefit studies, it has been indicated [Hessels et al., (2008), p.323] that in these type of studies material and immaterial risks and gains are brought into some decision function, posing it as explaining the decision or intent to start a business, often closely aligning with the third category where [Liang et al., (2015), p.166] it is defined that entrepreneurial intention is an individual's self-acknowledged conviction and plan to set up a new business venture at some point in the future, in response to certain factors. Beside this, [Carsrud and Brannback, (2011), p.9] in a discussion on the demise of the search for unique entrepreneurial traits, it was indicated that researchers may have turned to entrepreneurial intentions to understand this link between ideas and action. In further understanding the entrepreneurial intent [Kreuger et al., (2000), p.411], Shapero's model of the entrepreneurial event is most often used as a basis, where it is claimed that desirability, feasibility and a propensity to act are the most crucial factors influencing an individual's intention. This potentially then suggests that the character, nature and attitude that motivates individuals towards entrepreneurship, are not inherent in the individual, but rather flexible and change under different circumstances. While it is recognised that the intentional nature of entrepreneurial activity is highly important, the intentional models suggest that entrepreneurs are 'made' and not 'born'. This would assume that all individuals inherently possess goal-oriented characteristics, which [Pang, (2008), p.1] is suggested may not be the case, being detailed that a person either displays goal-directed behaviour or not under four differing variations, two of which cover avoidance behaviour.

Additionally indicated [Dana and Morris, (2011), p.149] is the importance of motive, skills and values in defining entrepreneurs, which may not be sufficiently explained through Shapero's model. Shapero's 'perceived desirability', although positioned as 
personal attractiveness, is explained rather as the degree to which an individual feels personally capable of starting a business, not necessarily motivated to. This explanation then [Kreuger et al., (2000), p.411] lacks definition of the actual strength of motivation of the individual, noting themselves the sampling issues of their research in using only senior university students, who are acknowledged as revealing vocational preference at a time when they face important and almost immediate career choices. Thus, although intentional models are a valuable tool in understanding the entrepreneurial process and nature of the actual behaviour, they may be deficient in the sought after explanation of certain specific attitudes that predict the intention itself.

In the final category, psychological motivation can be described as the forces within an individual that make up the course of the persons behaviour, comprising both intrinsic, or behaviour performed for its own sake, and extrinsic, behaviour performed to acquire material or other reward. Although there are numerous theories attempting to explain this motivation, in a management science context, the most popular are those based on the needs of the individual [Jones and George, (2009), p.463]. These main theories are divided into two groups, namely: process and content theories, investigated in the following section.

\section{Motivational theories}

Process theories of motivation can be said to centre on the 'how' and 'why' an individual's behaviour is energised, directed, sustained, and stopped [Pleitner, (1986), p.39]. The 'how' and 'why' refers then to the processes through which individuals choose various courses of action or behaviour. One of the most popular theories, defined by Vroom [Jones and George, (2009), p.463], is the expectancy theory. The theory argues that motivation is dependent on whether or not an individual believes their efforts will result in success, and whether or not this success will provide the desired rewards. In applying the expectancy theory [Hsu et al., (2014), p.121] in a longitudinal study, the possibility that the theory may be useful in predicting entrepreneurial intentions was supported. But, within the study it was too evident that Vroom's model is incomplete in explaining entrepreneurial motivation as it lacks the additional key of self-efficacy, or the individual's belief in their own ability or capacity to actually enter into their own business. Although being well known that Self-efficacy causally influences expected outcomes of behaviour, there exists some contradiction as to whether expected outcomes causally influence self-efficacy judgements. This is clarified [Bandura, (1994), p.71] specifically in that expected outcomes cannot causally influence self-efficacy. If the individual possesses a low self-efficacy, they are not likely to attempt to start their own business, despite the motivation explained in Vroom's model. The research on expectancy theory does however show that the setting of goals has a definitive effect on an individual's motivation and effort.

A further theory along these lines, goal-setting theory, is similar to the expectancy theory in that it presupposes that the individual is committed to the goal, and additionally that the goals are specific and difficult [Latham, (2003), p.309]. While this remains practical in an organisational environment, which the goal setting theory was primarily proposed for, both the specific nature of, and the difficulty of the goals, may not be in line with the modern day entrepreneur, who is likely to be required to entertain multiple 
goals of varying degree of difficulty. Many of the goals may too not be clearly evident or understood in the nascent stage of entrepreneurship. A further theory, equity theory, introduced by Adams, is primarily a workplace theory relating to employee satisfaction and dissatisfaction, largely around the issue of 'fairness' in the work environment [Robbins, (1993), p.203]. The theory then shows little practical value to entrepreneurial motivation and can be rather seen as an explanation 'after the fact' than as a predictor of behaviour.

As the process theories focus on establishing goals for directing behaviour as an important part of motivation, and are required to be equitable and deliver desirable outcomes the individual has an expectation of achieving, the structural environment they focus on is essentially then considered 'low risk'. This low risk outlook, inherently at odds with the essential characterisation of the entrepreneur in this context, renders the theories less valuable in understanding the entrepreneur's intrinsic motivation. The process theories then may not identify the right individual as a potential entrepreneur, but rather what to do once it is known who the potential individual is.

Important then in identifying the potential entrepreneur is that content theories of motivation centre on the 'who' is motivated [Pleitner, (1986), p.39], or the factors within an individual that energise, direct, and sustain behaviour. These theories are identified as need theories, with the most commonly known being Maslow's hierarchy of needs theory. In this theory, a need is defined as a physiological or psychological deficiency that an individual feels the urge to satisfy, thereby influencing the person's behaviour. Maslow proposed these needs exist in a hierarchical order and that only an unsatisfied need can influence behaviour [Jones and George, (2009), p.463]. In today's global economy, it was suggested [Idemobi, (2001), p.168] that citizens of different countries may differ in the need levels they require on Maslow's pyramid. In developing countries with lower standards of living, physiological and safety needs are likely to be the prime motivators of behaviour, as suggested in necessity entrepreneurship. In developed countries, with higher standards of living, needs related to personal growth and accomplishment may become more important, aligning more towards opportunity entrepreneurship.

Further assessment of Maslow's theory [Idemobi, (2001), p.168] indicates it as ethnocentric in that the hierarchy of needs fails to explain the difference between individualistic societies and collectivist societies. Maslow, being from the USA, a highly individualistic nation, formed his hierarchy of needs from an individualistic perspective where the needs and drives of individuals tend to be more self-centred than those in collectivist societies, with self-actualisation being the apex. In the collectivist societies, the needs of acceptance and community will outweigh the needs for freedom and individuality. Self-actualisation itself is difficult to define in that it potentially includes varying attributes that differ per individual, resulting in a difficult true understanding of the motivation of entrepreneurs. With Maslow himself having indicated his hierarchy of needs was more theoretical than normative [Kaur, (2013), p.1061].

More recently, Alderfer, in his ERG theory, collapsed Maslow's five levels of hierarchy into three universal categories of existence, relatedness and growth. Alderfer maintained the premise that as lower level needs are satisfied, the individual is then motivated to satisfy higher level needs. The main difference from Maslow being that Alderfer did not assume the same rigidity of the hierarchy where a lower level needs to be considerably satisfied before moving to a higher level, and that an individual could be motivated at more than one level at the same time [Jones and George, (2009), p.463]. It 
has been argued [Robbins, (1993), p.205] that Alderfer's Theory represented a more valid and dynamic version of the need hierarchy in that it is more consistent with individual differences among people, with variables such as education, childhood, and the cultural environment having an impact on the strength of the level of need on specific individuals, which allows for a concise analysis of the entrepreneurs motivation. However, Alderfer's theory allowing an individual to simultaneously satisfy any of the needs too represents a weakness, which together with the lack of research [Rauschenberger et al., (1980), p.654], leads to doubt of the actual worth of the theory. To accurately understand what need motivates an individual entrepreneur to behave a certain way, each individual entrepreneur or nascent entrepreneur would need to be assessed separately.

A further theory [Jones and George, (2009), p.463], Herzberg's two-factor approach, is documented as being different from Maslow and Alderfer in that he identified two sets of needs, motivation or satisfied needs, and hygiene or dissatisfied needs. $\mathrm{He}$ distinguished between these two factors of needs where motivation was related to the nature of the work itself, and hygiene was related to the physiological and psychological context in which the work is performed. This then implies that when hygiene factors such as basic income are adequate, then individuals will not be dissatisfied, but may not be motivated. To be motivated, the motivational needs, such as growth and responsibility, must too be satisfied. Despite the majority of empirical evidence invalidating the theory in a management context [Stello, (2011), p.1], it provides a foundation for later work on motivation, specifically on the basis of determining an individual's path to become an entrepreneur through necessity. In Hertzberg's model only the satisfied needs have the ability to motivate individuals, focusing largely on extrinsic rewards and the work itself, but lacking emphasis on explanation of intrinsic motivation, which represents a significant gap in explaining opportunity entrepreneurship.

In the most recent of theories, McClelland recognised that individuals ranked needs differently, identifying three specific needs, namely; need for achievement, need for power and need for affiliation. And while all three needs are present in individuals to some degree, the extent to which they are prioritised by individuals differs. The primary need in terms of entrepreneurial motivation was acknowledged as the need for achievement (n-ach) in a finding [McClelland and Winter, (1969), p.1] that the n-ach was the distinguishing factor separating motivation in small business entrepreneurs and other business leaders. This was affirmed by data in his 1965 study of Wesleyan graduates [McClelland, (1965), p.389] that n-ach was found to be a fairly stable behaviour characteristic that predisposes young men to enter entrepreneurial occupations, or function in conventional occupations in entrepreneurial ways. And, although this was a fairly gender biased study towards men, which was typical of that time, [Charles and Gherman, (2013), p.1345] a study of 20 female entrepreneurs in the USA discovered their primary motivation to be need for achievement, desire for independence, and need for greater job satisfaction.

In McClelland's need motivation theory, he identified three characteristics of entrepreneurs that related to their need for achievement, namely:

a desire to accept responsibility for solving problems, setting goals and reaching those goals through their own efforts

b a willingness to accept moderate risks, not as a function of chance, but of skill

c desire to know the outcomes of their decisions [Bull and Willard, (1993), p.183]. 
Considering the implications then of McClelland's view and the identified characteristics, the influence of different cultural capital on the factors affecting motivation is needed to be analysed and attempted to be better understood in order to define its significance on entrepreneurship. Figure 2 illustrates the framework developed to facilitate the understanding of the influence on $\mathrm{n}$-ach of similar and different cultural capital groups, in similar and different macro-economic policy environments, planned for further study by the writer to include United Kingdom English, Netherlands Dutch, and English and Afrikaans South African ethnic groups.

Figure 2 Framework comparing cultural impact

Cultural Capital Impacting n-Ach levels in Differing Macro-Economic Environments

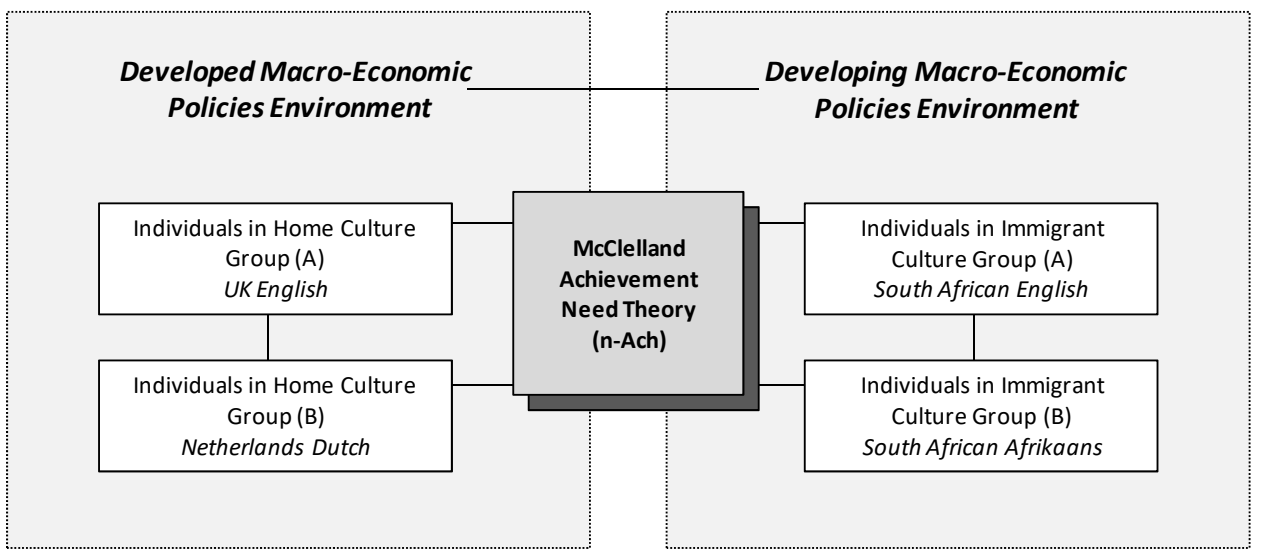

Comparing Home (Origin) and Immigrant (Descendant) Groups

\section{Cultural capital}

Culture as a concept has many definitions in literature, yet Hofstede's definition of "collective programming of the mind which distinguishes individual members of one group from another", provides a clear description in the context of this paper. Additionally highlighted is that culture has a long-term character, which is learnt consciously and unconsciously, and should be distinguished from both personality and human nature [Hofstede et al., (2010), p.3]. In an economic context, the value of this is termed cultural capital, which is defined [Throsby, (2001), p.166] as an asset which contains and creates value in addition to its existing economic value. Cultural capital may exist in either tangible or intangible form, occurring as tangible art works, painting, sculptures, buildings and the like, or as intangible items such as music, literature, values, beliefs, traditions and so on. Throsby too warns that the terminology cultural capital is used in other disciplines, such as sociology, where it may mean something different in its interpretation, adding that one of the known issues with cultural capital is that it is defined both in terms of its causes, and its effects. This then makes cultural capital somewhat elusive in actual quantification and validation of its value. 
In an attempt to understand this [Lamont and Lareau, (1988), p.153], cultural capital has been considered as a power resource, which includes access to technical, scientific, economic and/or political expertise. This power resource often facilitates access to organisational persons and positions, and simultaneously can be an indicator for class positions. It is important to identify that on an individual level, the family background is separable into three different components, namely; financial capital, human capital and social capital. Human capital is created by changes in individuals that bring about skills and capabilities enabling them to act in different ways, while social capital is described as changes in the relations among individuals that facilitate action [Coleman, (2010), p.95]. Social capital is defined by its function, and is productive, making possible the achievement of certain ends that in its absence would not be possible, taking the form of information that inheres in social relations. Clarified as it relates to entrepreneurship [Light and Dana, (2013), p.1], in that researchers wrongly conclude social capital as universally facilitating entrepreneurship, stating that social capital promotes entrepreneurship only when supportive cultural capital is in place.

\section{Implications of differing cultural capital groups}

The mere existence of cultural capital, or holding of a certain cultural value within an ethnic group, does not necessarily guarantee that it will lead to business success. Yet, it can be the core of what motivates an individual to action. Along with this, cultural capital certainly affects the entrepreneur's business decisions and management processes that may be different from the mainstream, and impact how the entrepreneurs interpret and respond to local and global market dynamics [Danes et al., (2008), p.229]. In a study on migrant entrepreneurs, [Hamilton et al., (2008), p.89] it is suggested that entrepreneurs, no matter where they are located, often tend to serve their own culture, and may even set themselves up in small communities and surround themselves by those of the same culture, forming the base of their customers. They further state that key aspects of culture are preserved, and are often used to differentiate the business, with migrant groups showing a strong link to the culture in which they grew up. Cultural habitus is summarised as identifying careers that are appropriate for individuals of their cultural group [Light and Dana, (2013), p.1], and if the same groups cultural capital does not support and endorse entrepreneurship as a career, then the group's strong social capital will not encourage entrepreneurship among the group members.

Reflecting on a conclusion by Shapero [Dana, (1996), p.65], culture is posed as an explanatory variable for entrepreneurial activity, or the lack thereof, noting that certain cultures may value entrepreneurship more than others. The case of small business in Xinjiang [Dana, (1998), p.123], it was found that for the Han-Chinese entrepreneurs, growth was related to advances in technology and government incentives, while for the Uygur entrepreneurs, growth was more simply a function of personal relations. Often seen is that more educated immigrants are also substantially more likely to use commercial and professional services, often irrespective of their background or culture. The difference of cultural capital then may be a larger impact than the nature of culture itself [Dana, (1996), p.65]. By reflecting on Brenner, who claimed that entrepreneurship is often a way to fight adverse circumstances, Dana further indicates that refugees, another form of migrant, are more likely to start businesses in host countries than in their 
own country of origin, suggesting that in times of transition, individuals may tend to become entrepreneurs, even if entrepreneurship was not their original goal.

And, although studies measuring differences between individuals in different cultures would generally report substantial differences between the cultures, they too often report considerable within culture variances that were typically not expected to be found [Rozin, (2003), p.273]. Corroborating this with his own unpublished results in a study of college students from the University of Pennsylvania and from the Utkal University in India, where there was reported great variation within same culture, even on items that were purposely selected to underline the cultural differences. Along with this, [Podrug et al., (2005), p.1] a study of cultural dimensions for Croatia, Slovenia and Bosnia and Herzegovina, showed some important similarities and differences among these countries that a short while ago shared the same political and economic context, being historically all federal units of the single Yugoslavia state. It can be expressed then that even within a country or a large cultural group, a variety of sub-cultures may exist, and an individual in this context is likely to be a member of at least one or more of these sub-cultures. Characteristics of these sub-cultures may, and is even likely, to overlap somewhat in terms of behaviour and motivation.

\section{Motivating cultures}

Business diversity in individualistic cultures is created by independent start-up ventures, and discovery of 'big ideas', most often in the pursuit of maximising financial success. An example of this is seen [Mirabela and Madela, (2013), p.1511] where cultures in which masculinity is pronounced, there likely exists a high need for accomplishment that is defined through economic success and wealth. In collectivist cultures, where often economic success is seen as only a means to achieve social goals and realise values, ventures are often evolutionary rather than revolutionary. Resources are leveraged internally by adhering to the shared values and norms of the cultural group. In this collectivist environment, commitment and trust, rather than the official contracts of the individualistic environment, motivate individuals to serve group interests [Heilbrunn, (2005) p.111].

These two concepts can be considered to be on opposite ends of the entrepreneurship motivation continuum, with a number of iterations in-between. A mid-way example of this is illustrated in a paper on Guanxi management in Chinese entrepreneurs [Fernandez and Vila Gisbert, (2010), p.1], where development and growth is high on the agenda as it relates to entrepreneurship, but Guanxi, or the social capital of 'connections', is highly relevant to achieve business success. Even for high potential new ventures, entrepreneurs need to manage Guanxi to obtain the advice and support of those in key positions in the network in order to achieve success. The Chinese concept of Guanxi stresses that business is always done between people, rather than between companies. In a similar cultural aspect, it is indicated [Hamilton et al., (2008), p.89] that there exists a high amount of customers within the same ethnicity in a study conducted on Chinese entrepreneurs in Manchester. Illustrating that no matter where they are located, entrepreneurs are likely to tend to largely serve their own culture.

Although certain universal principles of motivation seem to cut across cultural borders [Urban, (2007), p.82], it is further emphasised that an individual's cultural values will directly impact their perception of stimuli in work environments, and that these 
cultural values are in fact valuable criteria in evaluating and interpreting motivational tendencies. Within his own framework, Urban suggests that culture and beliefs act as catalysts rather than causal agents of entrepreneurial outcomes, meaning that although these should be cultivated to encourage entrepreneurship, they nevertheless may require a favourable environmental setting to be prosperous. This view is reinforced [Dana, (1996), p.65], by quoting Young as: "entrepreneurship occurs when a group has a low status, and has been denied access to mainstream society but still has more resources than other marginal groups". In this vein, Dana too expressed that with entrepreneurship being considered beneficial to a country, certain governments were even eager to encourage and attract immigrant entrepreneurs. The forces then stimulating both migrants and local groups towards entrepreneurship are often different, but often required to be the same.

\section{Limitations}

As this paper is specifically focussed on the impact of cultural capital on intrinsic need motivation (the 'who') as identified by achievement need motivation, the analysis does not include analysis of the impact of personality traits, nor does it include in-depth discussion on social capital and its effect. It is acknowledged that these do have a potential impact, however because the topic of entrepreneurship motivation is highly complex, the focus of this paper remains on understanding rather the impact of an individual's cultural capital on their $\mathrm{n}$-ach level in supporting entrepreneurship.

\section{Discussions and conclusions}

Through this paper, McClelland's achievement need motivation (n-ach) was identified as a relevant theory from the large body of literature that makes the closest effort to identify and explain the internal psychological forces that drives the individual to become an entrepreneur as defined in this text. Identifying the potential entrepreneur is considered the more important for institutions and policymakers to understand motivation of entrepreneurs, in order to facilitate and encourage them, as a force for creating economic value [United Nations, (2012), p.5]. Noted [Montana and Charnov, (2008), p.264], is that McClelland believed the need for achievement (n-ach) as the single most important causal factor driving entrepreneurship, which in turn can be considered to lead to economic development of a country. This motivation may, to a large extent, explain why individuals take financial risks, leave safe and predictable environments, and make certain personal sacrifices in order to pursue an uncertain future of starting a new business venture.

Additionally, understanding the impact of different group's cultural capital on these forces is proposed as highly important. And, although there is a significant amount of research that examines the motivation of entrepreneurs, much of the research has been conducted within developed countries. Thus, with many of the factors relating to motivation being common to entrepreneurs across some countries, there may exist further learning of similarities and differences between entrepreneurial motivations within cultures in developing versus developed countries. Quantitative study is planned by the writer to further investigate this impact of cultural capital on achievement need 
motivation levels as depicted in Figure 2. The research is conducted in cultural groups under differing macro-economic policy environments to support understanding of the relevant impact of cultural capital between similar cultural groups in their differing economic policy environments.

\section{References}

Alam, J. and Hossan, M.A. (2003) 'Linking between franchising networks for entrepreneurship and economic development - looking for a new model', EMNet Conference, p.1.

Bandura, A. (1994) 'Self-efficacy', in Ramachaudran, V.S. (Ed.): Encyclopaedia of Human Behaviour, Vol. 4, pp.71-81, Academic Press, New York.

Bhola, R., Verheul, I., Thurik, R. and Grilo, I. (2006) Explaining Engagement Levels of Opportunity \& Necessity Entrepreneurs, pp.1-33, Scientific Analysis of Entrepreneurship and SME's, EIM Business and Policy Research.

Bull, I. and Willard, G.E. (1993) 'Towards a theory of entrepreneurship', Journal of Business Venturing, No. 8, No. 3, pp.183-195.

Carsrud, A. and Brannback, M. (2011) 'Entrepreneurial motivations: what do we still need to know?', Journal of Small Business Management, Vol. 49, No. 1, pp.9-26.

Charles, V. and Gherman, T. (2013) 'Factors influencing peruvian women to become entrepreneurs', World Applied Sciences Journal, Vol. 27, No. 10, pp.1345-1354.

Coleman, J.S. (2010) 'Social capital and the creation of human capital', The American Journal of Sociology, Vol. 94, pp.95-120, Supplement: Organizations and Institutions, Sociological and Economic Approaches to the Analysis of Social Structure.

Dana, L.P. (1996) 'Self-employment in the Canadian sub-arctic: an exploratory study', Canadian Journal of Administrative Sciences, Vol. 13, No. 1, pp.65-77.

Dana, L.P. (1997) 'The origins of self-employment in ethno-cultural communities: distinguishing between orthodox entrepreneurship and reactionary enterprise', Canadian Journal of Administrative Sciences, Vol. 14, No. 1, pp.52-68.

Dana, L.P. (1998) 'Small business in Xinjiang', Asian Journal of Business and Information Systems, Vol. 3, No. 1, pp.123-135.

Dana, L.P. and Morris, M. (2011) 'Ethnic minority entrepreneurship', pp.149-157, World Encyclopedia of Entrepreneurship.

Dana, L.P. and Riseth, J.A. (2011) 'Reindeer herders in Finland: pulled to community-based entrepreneurship and pushed to individualistic firms', The Polar Journal, Vol. 1, No. 1, pp.108-123.

Danes, S.M., Lee, J., Stafford, K. and Heck, R.K.Z. (2008) 'The effects of ethnicity, families and culture on entrepreneurial experience: an extension of sustainable family business theory', Journal of Developmental Entrepreneurship, Vol. 13, No. 3, pp.229-268.

Dimitratos, P., Buck, T., Fletcher, M. and Li, N. (2015) The Motivational of International Entrepreneurship: The Case of Chinese Transnational Entrepreneurs, International Business Review, Corrected Proof.

Fernandez, I.A. and Vila Gisbert, J.E. (2010) Guanxi Management in Chinese Entrepreneurs: a Network Approach, pp.1-31, Fundacion BBVA, Working Paper Series, University of Valencia.

Hamilton, R., Dana, L.P. and Benfell, C. (2008) 'Changing cultures: an international study of migrant entrepreneurs', Journal of Enterprising Culture, Vol. 16, No. 1, pp.89-105.

Heilbrunn, S. (2005) 'Entrepreneurship, social capital and community development: the case of the Israeli Kibbutz', Journal of Rural Cooperation, Vol. 33, No. 2, pp.111-126.

Hessels, J., van Gelderen, M. and Thurik, R. (2008) 'Entrepreneurial aspirations, motivations, and their drivers', Small Business Economics, Vol. 31, No. 3, pp.323-339. 
Hofstede, G., Hofstede, G.J. and Minkov, M. (2010) Cultures and Organizations: Software of the Mind, 3rd ed., pp.3-24, McGraw-Hill, New York, New York.

Hsu, D.K., Shinnar, R.S. and Powell, B.C. (2014) 'Expectancy theory and entrepreneurial motivation: a longitudinal examination of the role of entrepreneurship education', Journal of Business and Entrepreneurship, Vol. 26, No. 1, pp.121-140.

Idemobi, E.I. (2011) 'The implication of Abraham Maslow's hierarchy of needs theory to business activities in Nigeria', African Journal of Social Sciences, Vol. 1, No. 1, pp.138-178.

Jones, G.R. and George, J.M. (2009) Contemporary Management, 6th ed., pp.463-488 McGraw-Hill/Irwin, New York, NY.

Kaur, A. (2013) 'Maslow's need hierarchy theory: applications and criticisms', Global Journal of Management and Business Studies, Vol. 3, No. 10, pp.1061-1064.

Kirkwood, J. (2001) Defining our Entrepreneurs, Vol. 15, No. 10, pp.22-24, New Zealand Business.

Kreuger, N.F., Reilly, M.D. and Carsrud, A.L. (2000) 'Competing models of entrepreneurial intentions', Journal of Business Venturing, Vol. 15, Nos. 5-6, pp.411-432.

Lamont, M. and Lareau, A. (1988) 'Cultural capital: allusions, gaps and glissandos in recent theoretical developments', Sociology Theory, Vol. 6, No. 2, pp.153-168.

Latham, G.P. (2003) 'Goal setting: a five-step approach to behavioural change', Organizational Dynamics, Vol. 32, No. 3, pp.309-318.

Liang, C.T., Chia, T.L. and Liang, C. (2015) 'Effect of personality differences in shaping entrepreneurial intention', International Journal of Social Science, Vol. 6, Nos. 1-4, pp.166-176.

Light, I. and Dana, L.P. (2013) 'Boundaries of social capital in entrepreneurship', Entrepreneurship Theory and Practice, Vol. 37, No. 3, pp.603-624.

Mc Clelland, D.C. and Winter, D.G (1969) Motivating Economic Achievement, p.1, Free Press, New York.

McClelland, D.C. (1965) 'N achievement and entrepreneurship', Journal of Personality and Social Psychology, Vol. 1, No. 4, pp.389-392.

Mirabela, M. and Madela, A. (2013) Cultural Dimensions and Work motivation in the European, pp.1511-1519, Union The University of Oradea, Co-funded by the European Social Fund.

Montana, P.J. and Charnov, B.H. (2008) Management, 4th ed., p.246, Barron's Educational Series, Hauppauge, New York.

Pang, J.S (2008) The Achievement Motive: A Review of Theory and Assessment of $N$ Achievement, Hope of Success and Fear of Failure, pp.1-65, Nanyang Technological University, Singapore.

Pleitner, H.J. (1986) 'Entrepreneurs and new venture creation: some reflections of a conceptual nature', Journal of Small Business and Entrepreneurship, Vol. 4, No. 1, p.39.

Podrug, N., Pavicic, J. and Vjekoslav, B. (2005) Cross-Cultural Comparison of Hofstede's Dimensions and Decision Making Style within CEE Context, Graduate School of Economics and Business Zagreb, pp.1-16.

Rauschenberger, J., Schmitt, N. and Hunter, J.E. (1980) 'A test of the need hierarchy concept by a Markov model of change in need strength', Administrative Science Quarterly, Vol. 25, No. 4, pp.654-670.

Robbins, S.P. (1993) Organizational Behaviour, 6th ed., pp.205-235, A Simon and Schuster Company, Eaglewood Cliffs, New Jersey.

Rozin, P. (2003) 'Five potential principles for understanding cultural differences in relation to individual differences', Journal of Research in Personality, No. 37, No. 4, pp.273-283.

Solymossy, E. (2005) 'Entrepreneurship in extreme environments: building an expanded model', International Entrepreneurship and Management Journal, Vol. 1, No. 4, pp.501-518. 
Stello, C.M. (2011) Herzberg's Two-Factor Theory of Job Satisfaction: an Integrative Literature Review, pp.1-32, Department of Organizational Leadership, Policy, and Development, College of Education and Human Development, University of Minnesota.

Stephan, U., Hart, M. and Drews, C. (2015) Understanding Motivations for Entrepreneurship: a Review of Recent Research Evidence, pp.1-52, Enterprise Research Centre, Rapid Evidence Research Paper.

Throsby, D. (2001) 'Chapter 19: cultural capital', in Towse, R. (Ed.): A Handbook of Cultural Economics, pp.166-169, Edward Elgar Publishing Limited, Cheltenham.

Ucbasaran, D., Westhead, P., Wright, M. and Flores, M. (2010) 'The nature of entrepreneurial experience, business failure and comparative optimism', Journal of Business Venturing, No. 25 , No. 6, pp.541-555.

United Nations (2012) Conference on Trade and Development (UNCTAD) - Entrepreneurship Policy Framework and Implementation Guide, p.5, New York and Geneva.

Urban, B. (2007) A Framework for Understanding the Role of Culture in Entrepreneurship Acta Commercii, University of Johannesburg, pp.82-95.

Valdez, M.E., Doktor, R.H., Singer, A.E. and Dana, L.P. (2011) 'Impact of tolerance for uncertainty upon opportunity and necessity entrepreneurship', Human Systems Management, Vol. 30, No. 3, pp.145-153.

Zimmerer, T.W. and Scarborough, N.M. (2008) Essentials of Entrepreneurship and Small Business Management, p.5, Pearson Education Inc., Upper Saddle River, New Jersey. 